\title{
SHORT SALE AND INDEX FUTURES \\ MISPRICING: EVIDENCE FROM \\ THE WARSAW STOCK EXCHANGE
}

\section{Edyta Marcinkiewicz*}

\begin{abstract}
The study attempts to assess the effects of lifting short sale restrictions on the Warsaw Stock Exchange in terms of futures pricing efficiency. The approach implemented in the article involves evaluation and comparison of the mispricing series of the WIG20 index futures listed on the WSE, in a one-year time span before and after the regulatory change introduced in 2010. The results show that lifting short sale constraints has increased the efficiency of the Polish futures market. There was a decline both in the number of mispricing occurrences, and in the mean level and dispersion of deviations from the fair values, especially with regard to underpriced contracts series. The study reveals that, in contrast to the pre-event period, after the regulatory change the arbitrage opportunities were virtually absent for investors bearing the highest transaction costs.
\end{abstract}

Keywords: futures mispricing, short sale, cost-of-carry, Warsaw Stock Exchange JEL Classification: G12, G13

\section{Introduction}

July 2010 saw the introduction of legislative and organizational changes concerning short selling on the Warsaw Stock Exchange (WSE), long-awaited by investors. The changes were made with a high level of involvement of the exchange authorities, who perceived the new regulations as a chance for further growth in the equity and derivatives markets. On the eve of their introduction, the WSE President said: "We are very intent on introducing this instrument. Short selling is not just a way to make profit from prices' decline, but it improves the credibility and pricing of securities listed on the exchange." (WSE press conference, April 14, 2010). However, the initiatives aimed at making short selling more accessible to investors were undertaken at a rather unfavourable time. The fear of possible dangerous consequences of short selling on exchanges grew stronger during the global financial crisis that began in 2008, and many institutions supervising local stock markets introduced temporary or permanent restrictions on short sales. As showed by Copeland and Elliott (2013), the actual value of these short-sales bans was limited. Nevertheless, at that time short selling was regarded as a threat that might destabilize the market, enable price manipulation, or even lead to market crashes. Positive aspects of allowing short selling mostly concern the practical facilitations for investors who can benefit also from the downward price trends. That is the reason why the number of exchanges allowing short selling has been growing steadily in response to investor demand, and the global trade volume in this area has been increasing since the 1990s (Kern, 2010). Some empirical studies prove that lifting short sale restrictions can influence the market in terms of enhancing the pricing of stock and related derivatives, and it is seen as a factor that increases

Edyta Marcinkiewicz, Department of Management, Lodz University of Technology, Lodz, Poland (edyta.marcinkiewicz@p.lodz.pl). 
the liquidity of listed securities (Pope and Yadav, 1994; Figlewski, 1981; Diamond and Verrecchia, 1987; Woolridge and Dickinson, 1994; Charoenrook and Daouk, 2005). The value of short sale transactions as an indicator of investor expectations has also been emphasized by Ackert and Athanassakos (2005), Aitken et al. (1998), and Asquith et al. (2004). On the other hand, there are some studies suggesting that short selling is a threat to stock markets. The risk of faster declines in prices of stocks subject to short sales, in comparison to stocks for which short selling is not allowed, during bear market periods is illustrated by the results presented by Chan et al. (2010). Another study by Bris et al. (2007) shows that markets that allow short selling experienced slightly increased left-hand return asymmetry.

One of the expected positive effects of the introduction of short selling on the Warsaw Stock Exchange was the improvement of the futures market pricing. The persisting discrepancy between the market prices of futures and the theoretical fair values that meet the no-arbitrage condition is quite common on the contemporary markets. In the existing literature on the subject, many causes have been suggested for futures mispricing series (e.g. Cornell and French, 1983; Andani et al., 2009, Wagener et al., 2010; Brailsford and Cusak, 1997; Zhang and Lai, 2006), but most of them originate from the limitations of arbitrage. One of the reasons for an imperfect arbitrage mechanism, which brings spot and futures prices together, seems to be the lack of short sale availability (Pope and Yadav, 1994; Kempf, 1998; Fung and Jiang, 1999; Wang, 2010). McMillan and Ülkü (2009) show that on an immature market, the mispricing of index futures results not only from practical difficulties with short sale execution, but also from behavioural factors. In line with their findings, in the case of the Polish stock market, the two most likely causes of long-lasting index futures mispricing can be distinguished. The first one is the fact that the futures market is dominated by individual investors, identified with uninformed trading and focussed primarily on speculation strategies. The second one regards considerable restrictions on short selling.

The direct motivation for considering this subject was the regulatory changes made in July 1, 2010 on the Warsaw Stock Exchange, facilitating short sale of stocks. The present study contributes to the existing literature in two aspects. Firstly, in the case of the Polish capital market, there is an empirical gap with regard to the subject of short sale. Due to the very scarce availability of short selling before 2010, it is a new issue and the implications of these changes have not been empirically investigated yet. Secondly, the present work can be regarded as a complement to the study by Bohl et al. (2011), which analyses the influence of the first of the two aforementioned most likely causes of long-lasting index futures mispricing, namely structural changes of investors, on the market pricing of WIG20 futures. Their results imply that admitting investment funds to the futures market enhanced futures pricing efficiency. This study focuses on the second factor affecting index futures mispricing. It analyses whether lifting short sale constraints resulted in the further reduction of futures mispricing series even though individual investors were still a dominant group on the futures market.

\section{Institutional Setting}

\subsection{WIG20 cash and futures market}

The WIG20 index was first published by the Warsaw Stock Exchange on April 16, 1994. It is composed of stocks of a maximum of 20 of the largest and most liquid companies traded on the main floor of the WSE. It is a price index, computed without taking into 
account income from dividends. According to the criteria of qualification for the index portfolio, the market value of a constituent company's free-traded stocks must be at least $€ 14$ million, and the value of transactions involving the company stocks in at least half of all trading sessions in the last six months must be at least $€ 20$ million. Companies meeting the above criteria are ranked according to stock-trading volume (weight 0.6 ) and the value of free-traded stock (weight 0.4). The 20 highest-ranked companies are included in the index, with the restriction that there may be no more than five companies from the same sector. The composition of the index is changed four times a year - quarterly adjustments are made on the third Friday of June, September and December, and an annual adjustment takes place in March.

The WIG20 is limited to 20 blue chips, a small number comparing to other world indexes. Nonetheless, it accounts for about $80 \%$ of the entire stock market trade value, as the great majority of the more than 400 companies listed on the WSE have marginal liquidity. The total capitalization of companies included in the WIG20 accounts for $65 \%$ of the exchange capitalization. The narrowness of the index makes the stocks relatively easy to replicate. Therefore, arbitrage with a perfectly matched basket between the spot and futures markets is feasible, and tracking error risk is low. In addition, the WIG20 is characterized by high concentration. The concentration ratio defining the total percentage influence of the prices of the five largest companies in WIG20 on the price of the index has ranged between $50 \%$ and $65 \%$ for many years. The larger the share of stocks of a given company in the index, the stronger its influence on the index price, which is of significance to investors securing a stock portfolio with index futures. Investors holding the largest companies on the exchange in their portfolios, instead of the whole index, may hedge equally well without the need for full replication of the index being the underlying instrument of WIG20 contracts.

The futures market on the WSE is of special importance to the Polish capital market, as these instruments have dominated the trading structure of the Warsaw exchange. WIG20 futures were the first derivatives introduced to the WSE (in 1998), and in comparison with other derivatives they gained the highest popularity on the trading floor. The trading schedule for WIG20 contracts provides that constantly there are four series present on the market, each of which expires in one of the months of March, June, September and December. Though the WSE offers trading in futures based on currencies, equity, other stock-market indexes and options, no other derivative can be compared to WIG20 futures in terms of trade volume and liquidity. At the end of 2010, futures trading on the WSE was worth PLN 660,943 million, which exceeded by more than $40 \%$ the value of equity trading in the same period. The highest trading volume was recorded in 2007. In that year, during a bull market period, the value of futures trading reached PLN 674,132 million. The size of futures trading has remained constantly higher (in value) than equity trading since 2001, but in recent years this dominance has become even more distinct. However, although the index futures market enjoys very high liquidity and volume, for a long time it has operated in terms of considerable separation from the spot market. This situation has several causes, all of which have their roots in the insufficient maturity of the Polish capital market. In spite of the significant development of the Polish stock exchange in recent years, results of analyses of its effectiveness and maturity are still mixed (Strawiński and Slepaczuk, 2008; Potocki and Swist, 2012; Graff and Kaczkowska, 2013).

The WSE futures market has grown primarily through the activity of individual investors pursuing speculative strategies. In the initial phase of the WSE futures market, 
they were responsible for over $90 \%$ of trade volume. They still dominate in the investor structure, and there is an upward trend in numbers of individual traders on the derivatives market. The very high percentage of individual investors in derivatives trading on the WSE makes this market appear rather atypical. At the same time, however, there is a considerable influx of institutional and foreign investors, reducing the overall percentage of trading accounted for by individuals. Notwithstanding, they are still the dominant group in the futures market, accounting for about a 50\% share. There are several reasons for this situation (Bohl et al., 2010). Firstly, there is a relatively low multiplier set for contracts, equal to PLN 10 in the case of WIG20 contracts. This makes them accessible to individuals with limited financial resources. Secondly, in the case of individual investors, entry to the futures market is not obstructed by formal barriers. Thirdly, the previous legal regulations made it difficult for institutional investors such as investment funds to gain access to the futures market. Only the regulations introduced in 2004 and subsequent changes enabled the broader use of derivatives in the portfolios of investment funds, of both open and closed type. On the other hand, pension funds are not permitted to invest in derivatives at all. There is, however, a distinct increase in the share of trading volume accounted for by institutions - banks, investment funds and insurance companies.

\subsection{Short sale constraints on the WSE}

Until July 2010, short selling on the WSE was very tightly restricted. The legal framework was very strict as concerns rules on securities lending. Short selling was only allowed with respect to the stocks of companies whose market value was at least $€ 100$ million. Furthermore, at least one liquidity requirement had to be met with respect to the lent securities, that is, either the average daily value of trading in the security had to be no lower than $€ 250,000$, or the average daily number of transactions involving the security had to be at least 50 . Before the introduction of the changes in July 2010, not many companies met those conditions. Short selling was very rarely used, largely because of the regulations requiring that securities could be sold only after settlement of the lending transaction, i.e. registration of the securities on the seller's account. Other factors limiting short selling were the high costs, the need to provide high initial and additional margin, insufficient supply, and unclear tax regulations relating to short sale transactions.

As of July 1,2010, the new and simpler rules on short selling came into force on the Warsaw Stock Exchange. The new rules allow the short sale of the stock of all companies included in the WIG20 and of the first 140 companies included in the liquidity rating system that meet the additional conditions referring to the trade value. Short selling was also enabled in the case of securities of large debuting companies. The group of instruments in which short selling is permitted also includes securities issued by the Treasury and the National Bank of Poland. Market makers were also allowed to perform short sales of securities of companies not meeting the above criteria, provided that they are ranked at or above \#140 in the liquidity rating. The list of securities available for short selling on the WSE is updated as standard eight times a year - four times due to the quarterly updates of the WIG20 composition, and four times due to the quarterly updates of the liquidity rating. The number of individual stocks qualifying for client transactions is not fixed, ranging from 30 to 40 , while it stands at 140 for market makers. However, actual trading generally involves the stocks of 20-30 companies (Table 1), depending on the month, and most of these are included in the WIG20. The share of these companies in monthly short sale trading 
usually exceeds $95 \%$, often reaching as much as $99 \%$. One might thus form a thesis that if there is a short sale regulation mechanism on the WSE equity market, enforced through arbitrage, it primarily concerns companies included in the WIG20 and derivatives whose underlying instruments are stocks of the companies in the index.

Table 1 | Monthly Statistics for Short Sale on WSE

\begin{tabular}{|l|c|c|c|}
\hline Month & $\begin{array}{c}\text { Total number of stocks } \\
\text { traded short }\end{array}$ & $\begin{array}{c}\text { Number of WIG20 } \\
\text { stocks traded short }\end{array}$ & $\begin{array}{c}\text { \% of WIG20 stocks } \\
\text { turnover in total short } \\
\text { sale turnover }\end{array}$ \\
\hline Jul-10 & 25 & 19 & $99.34 \%$ \\
\hline Aug-10 & 26 & 19 & $99.67 \%$ \\
\hline Sep-10 & 17 & 12 & $99.96 \%$ \\
\hline Oct-10 & 30 & 20 & $98.34 \%$ \\
\hline Nov-10 & 29 & 19 & $97.28 \%$ \\
\hline Dec-10 & 25 & 17 & $97.30 \%$ \\
\hline Jan-11 & 27 & 20 & $98.33 \%$ \\
\hline Feb-11 & 31 & 19 & $99.38 \%$ \\
\hline Mar-11 & 34 & 14 & $96.40 \%$ \\
\hline Apr-11 & 21 & 19 & $99.33 \%$ \\
\hline May-11 & 31 & 20 & $91.65 \%$ \\
\hline Jun-11 & 31 & $19.11 \%$ \\
\hline
\end{tabular}

Source: Own calculation based on the WSE Monthly Bulletins

The changes introduced in 2010 greatly increased the volume of short sale transactions in shares. In 2002, the value of short sale trading amounted to PLN 25 million, in 2005 to PLN 3 million, and in 2009 the number of such transactions amounted to 35,432 , with a total value around PLN 1.4 million. In just the first three months after the changes that is from July to September 2010, the trade volume increased to 14 million securities with a total value of PLN 576 million. The value of short sale transactions in the whole of 2010 was over PLN 1.1 billion, and in 2011 it reached PLN 2.7 billion. The short sale volume in particular months was very diverse. In theory, it should correlate with downward trends on the equity market. Stock market declines are a prerequisite for short selling, as such transactions generate profit when stock prices go down. However, on the WSE, the volume of monthly short sale trading seems to be independent of periodic declines in stock prices. High sales were recorded during both downward and upward movements. Short selling enjoyed its least popularity during horizontal trends, i.e. during the market stagnation which occurred from December 2010 to January 2011 and in April 2011. 


\section{Data and Methodology}

The analysis employs 5-minute intraday data of Polish blue-chip index WIG20 and WIG20 futures (FW20), both listed on the Warsaw Stock Exchange, within a period of 2 years from July 2009 to June 2011. Futures price series only include the series of contracts that are closest to maturity, i.e. they cover observations from approximately 60 days before expiration. This enables the examination of futures prices at their highest liquidity. Both WIG20 and FW20 series were divided into two sub-samples with a comparable duration of one year. The first sub-sample covers the period of one year before the introduction of the regulatory changes concerning short selling on the WSE, namely from July 1, 2009 to June 30, 2010. Similarly, the second sub-sample covered the listing period from July 1, 2010 to June 30, 2011, namely a one-year period from the introduction of the new short selling rules on the WSE.

The study of FW20 mispricing involves the measure of futures overpricing or underpricing applied by Butterworth and Holmes (2000):

$$
M_{t}=\frac{F_{t}-F V_{t}}{S_{t}} \cdot 100 \%
$$

The ratio between the actual market price of a futures contract $F$ and its theoretical fair value price $F V$, standardized with reference to the spot price $S$ specifies the percentage value of mispricing, i.e. the degree of underpricing or overpricing of the derivative on the exchange market in relation to its true value. In further empirical analyses, the fair value $F V$ is calculated on the basis of the cost-of-carry formula proposed by Cornell and French (1983). The cost-of-carry model for stock and index futures is expressed as follows:

$$
F V_{t}=S_{t} e^{(r-d) T}
$$

where $r$ denotes the risk-free rate, $d$ is the dividend yield, and $T$ denotes the time to maturity. The proxy of the risk-free rate used in the study is the Warsaw Interbank Offered Rate (WIBOR) published on a daily basis. The daily data on dividend yield are provided by the WSE. For the purposes of this study the tax-adjusted dividend yield is applied.

The cost-of-carry formula emphasizes the strong synchronicity between spot and futures prices, and implies the substitutability of futures and their underlying instruments. However, it is valid on the assumption that the market is frictionless. Previous studies on the subject have suggested other models that are adjusted to more realistic market conditions, for example, the models developed by Hsu and Wang (2004), Ramaswamy and Sundaresan, (1985), Hemler and Longstaff (1991). Nevertheless, the present paper employs the costof-carry model. Firstly, as various studies prove (e.g. Brailsford and Cusack, 1997; Wang and Hsu, 2006; Chow et al., 2000), cost-of-carry - despite its simplicity - does not differ much in terms of performance from other models. Secondly, the formula for futures pricing in this analysis is intended for comparing change over two periods - before and after the introduction of new regulations on short selling. Therefore, details concerning the model's performance are of minor importance, as it will only be used for observing tendencies.

Considerable mispricing occurs only if the difference between the market and fair value exceeds the costs of performing arbitrage transactions consisting of taking opposite positions on the markets of the underlying and derivative instruments. Therefore, when 
assessing the degree of derivative overpricing or underpricing, it is necessary to consider the transactional costs. When the mispricing level is within the no-arbitrage limit, the market pricing of futures may still be deemed effective. It is assumed that a contract is overpriced if $M_{t}>T C$, and that it is underpriced if $M_{t}<-T C$, where $T C$ denotes the percentage value of transactional costs between the spot and futures markets. In this study, the $M_{t}$ series is analysed with respect to four variants of transaction costs: $0 \%, 0.3 \%, 0.6 \%$ and $0.9 \%$. The thresholds are adopted in line with Białkowski and Jakubowski (2008). They estimated the level of costs applicable on the WSE, and found that costs of $0.3 \%$ are borne by privileged investors (stock exchange members), costs of $0.6 \%$ by large institutions, and costs of $0.9 \%$ by small investors. These values represent market impact costs, round-trip commission for futures market and round-trip commission for spot market. In this study the same values are applied and they serve as reference levels for mispricing series.

In the comparison of the two periods - before and after the introduction of new regulations on the WSE - other factors affecting WIG20 futures mispricing were also analysed. As noted by MacKinlay and Ramaswamy (1988) and by Buchler and Kempf (1995), mispricing is reduced as the contract approaches maturity. Another factor that might directly influence the level of mispricing is volatility. Yadav and Pope (1994) found that the higher volatility, the higher is contract over- and underpricing. The regression equation reflecting the influence of short sale restrictions, time to maturity, and volatility on mispricing was formulated on a daily basis:

$$
\left|d_{i}\right|=\alpha_{0}+\alpha_{1}(T-i)+\alpha_{2} D_{i}+\alpha_{3} V_{o l}+\varepsilon_{i}
$$

where $d_{i}=\sum_{t=1}^{N} M_{t, i} / N, N$ is the number of observations on day $i, D_{i}$ is a dummy variable equal to 1 when short selling was constrained and 0 when restrictions were lifted, $\mathrm{Vol}_{i}$ denotes daily realized volatility calculated according to the Equation $\sum_{t=1}^{N} R_{t, i} \cdot R_{t, i}$, where $R_{t, i}=\ln \left(S_{t, i} / S_{t-1, i}\right)$, and $\varepsilon_{i}$ is an error term. Apart from short sale conditions, estimation of the above equation also enables control over other factors possibly affecting the level of mispricing.

\section{Empirical Results}

The preliminary stage of the study included the visual analysis of the mispricing series developed according to Equation 1. As shown in Figure 1, the periods before and after the introduction of short sale facilitations on the WSE were significantly different. The scope of mispricing was considerably reduced after July 1, 2010, when the new regulations came into force.

This corresponds to the results of the calculations presented in Table 2. In all subperiods under study and under every variant of transaction costs, the number of WIG20 contract mispricing occurrences $\left(M_{t}\right)$ was counted. It was assumed that mispricing only occurs when $M_{t}$, according to Equation 3, meets the condition $\left|M_{t}\right|>T C$, i.e. when the absolute over- or underpricing of a contract is higher than the percentage value of the cost of performing arbitrage transactions on the spot and futures markets. Moreover, the numbers of overpricing $\left(M_{t}>T C\right)$ and underpricing $\left(M_{t}<-T C\right)$ occurrences in the time under study were specified separately. In addition, absolute values $\left(\left|M_{t}\right|\right)$ were computed. Calculation of statistical measures (mean, median, and standard deviation) helped to conclude how the futures pricing efficiency changed over time with reference to the value of the underlying 
instrument. A relative frequency of occurrence was also calculated, specifying the percentage of futures over- or underpricing occurrences where the costs $T C$ were exceeded, out of the total number of $M_{t}$ values obtained.

Figure 1 | Plot of WIG20 Index Futures Mispricing before and after Regulatory Changes
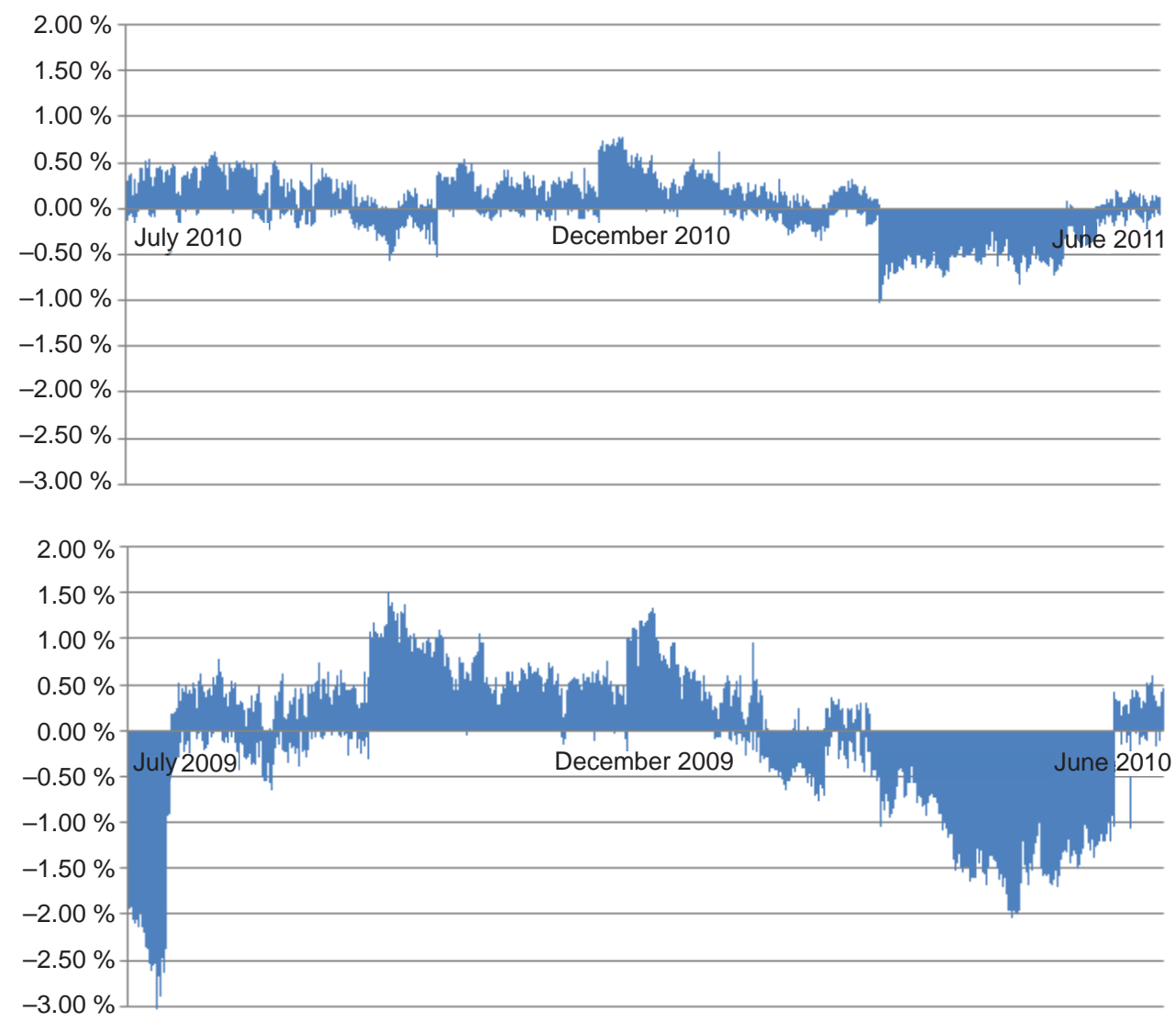

Source: Authors' calculations

Much greater differences between market pricing and the fair value of futures were observed in the first sub-period, while in the second sub-period contract mispricing (taking into account transactional costs) occurred much less frequently, except for under the hypothetical cost-free variant. In the case of zero transactional costs, the distribution of under- and overpricing occurrences is similar in both sub-samples. In the case of nonzero transactional costs, however, the mispricing distribution differed between the periods studied. It should be noted that under the $0.6 \%$ and $0.9 \%$ cost, futures were more often underpriced than overpriced, which means that the contract price was lower than would be expected according to its true value developed by the cost-of-carry model. However, what is most revealed about the changes in mispricing series is the analysis of their mean levels. The mean underpricing at the cost levels of $0 \%, 0.3 \%$, and $0.6 \%$ was much more radically 
reduced than the mean overpricing. After July 1, 2010, both overpricing and underpricing virtually disappeared when the $0.9 \%$ cost variant was considered. This means that smaller investors had no opportunities for arbitrage. Very large disproportions between the first and second sub-periods are also visible with regard to the variability of the $M_{t}$ values. For example, under the $0.3 \%$ cost variant, the standard deviation differed markedly between the two sub-periods, amounting to $0.94 \%$ in the first one and $0.45 \%$ in the second one. As in the case of the means, the dispersion of underpricing was more significantly reduced than that of overpricing.

Table 2 | Statistics of WIG20 Index Futures Mispricing

\begin{tabular}{|c|c|c|c|c|c|c|c|c|c|c|c|c|c|c|}
\hline & \multicolumn{7}{|c|}{ Period 1 (pre event) } & \multicolumn{7}{|c|}{ Period 2 (post event) } \\
\hline & $N$ & Mean & Med & Std & Min & Max & $\begin{array}{c}\text { Freq } \\
(\%)\end{array}$ & $N$ & Mean & Med & Std & Min & Max & $\begin{array}{c}\text { Freq } \\
(\%)\end{array}$ \\
\hline \multicolumn{15}{|c|}{ Panel A: $\mathbf{0 . 0 \%}$ Transaction Cost } \\
\hline$M$ & 21,693 & -0.11 & 0.11 & 0.76 & -3.09 & 1.52 & 100 & 22,588 & 0.01 & 0.05 & 0.28 & -1.03 & 0.78 & 100 \\
\hline$|M|$ & 21,693 & 0.58 & 0.41 & 0.51 & 0.00 & 3.09 & 100 & 22,588 & 0.22 & 0.17 & 0.17 & 0.00 & 1.03 & 100 \\
\hline$M>T C$ & 12,615 & 0.40 & 0.33 & 0.29 & 0.00 & 1.52 & 58 & 13,259 & 0.19 & 0.16 & 0.15 & 0.00 & 0.78 & 59 \\
\hline$M<-T C$ & 9,078 & -0.82 & -0.74 & 0.63 & -3.09 & 0.00 & 42 & 9,329 & -0.25 & -0.21 & 0.20 & -1.03 & 0.00 & 41 \\
\hline \multicolumn{15}{|c|}{ Panel B: $0.3 \%$ Transaction Cost } \\
\hline$M$ & 13,565 & -0.22 & 0.31 & 0.94 & -3.09 & 1.52 & 63 & 6,582 & -0.08 & -0.34 & 0.45 & -1.03 & 0.78 & 29 \\
\hline$|M|$ & 13,565 & 0.83 & 0.70 & 0.49 & 0.30 & 3.09 & 63 & 6,582 & 0.45 & 0.43 & 0.11 & 0.30 & 1.03 & 29 \\
\hline$M>T C$ & 6,948 & 0.60 & 0.51 & 0.25 & 0.30 & 1.52 & 32 & 2,789 & 0.43 & 0.40 & 0.11 & 0.30 & 0.78 & 12 \\
\hline$M<-T C$ & 6,617 & -1.08 & -1.05 & 0.55 & -3.09 & -0.30 & 31 & 3,793 & -0.46 & -0.45 & 0.11 & -1.03 & -0.30 & 17 \\
\hline \multicolumn{15}{|c|}{ Panel C: $0.6 \%$ Transaction Cost } \\
\hline$M$ & 7,706 & -0.53 & -0.93 & 1.10 & -3.09 & 1.52 & 36 & 711 & -0.05 & -0.60 & 0.66 & -1.03 & 0.78 & 3 \\
\hline$|M|$ & 7,706 & 1.14 & 1.04 & 0.44 & 0.60 & 3.09 & 36 & 711 & 0.66 & 0.65 & 0.06 & 0.60 & 1.03 & 3 \\
\hline$M>T C$ & 2,738 & 0.86 & 0.84 & 0.18 & 0.60 & 1.52 & 13 & 331 & 0.66 & 0.65 & 0.04 & 0.60 & 0.78 & 1 \\
\hline$M<-T C$ & 4,968 & -1.29 & -1.22 & 0.46 & -3.09 & -0.60 & 23 & 380 & -0.67 & -0.64 & 0.07 & -1.03 & -0.60 & 2 \\
\hline \multicolumn{15}{|c|}{ Panel D: $0.9 \%$ Transaction Cost } \\
\hline$M$ & 5,030 & -0.91 & -1.21 & 1.07 & -3.09 & 1.52 & 23 & 5 & -0.99 & -0.99 & 0.03 & -1.03 & -0.95 & 0 \\
\hline$|M|$ & 5,030 & 1.35 & 1.23 & 0.41 & 0.90 & 3.09 & 23 & 5 & 0.99 & 0.99 & 0.03 & 0.95 & 1.03 & 0 \\
\hline$M>T C$ & 1,038 & 1.06 & 1.04 & 0.11 & 0.90 & 1.52 & 5 & 0 & - & - & - & - & - & 0 \\
\hline$M<-T C$ & 3,992 & -1.42 & -1.31 & 0.42 & -3.09 & -0.90 & 18 & 5 & -0.99 & -0.99 & 0.03 & -1.03 & -0.95 & 0 \\
\hline
\end{tabular}

Notes: Values of mean, median, standard deviation, minimum and maximum expressed in percentage point units. Freq specifies the percentage of futures over- or underpricing occurrences when the costs TC were exceeded, out of the total number of $M$.

Source: Authors' calculations 


\begin{tabular}{|l|c|c|c|}
\hline & $\begin{array}{l}\mathbf{H}_{0}: \mu_{1}=\mu_{2} \\
H_{1}: \mu_{1}>\mu_{2}\end{array}$ & $\begin{array}{l}H_{0}: \sigma_{1}=\sigma_{2} \\
H_{1}: \sigma_{1}>\sigma_{2}\end{array}$ & $\begin{array}{c}H_{0}: F_{1}(x)=F_{2}(x) \\
H_{1}: F_{1}(x) \neq F_{2}(x)\end{array}$ \\
\hline $\mathbf{0 . 0 \%}$ Transaction Cost & $98.35^{* * *}$ & $8.58^{* * *}$ & $4,850.81^{* * *}$ \\
\hline $\mathbf{0 . 3 \%}$ Transaction Cost & $86.94^{* * *}$ & $20.02^{* * *}$ & $2,820.83^{* * *}$ \\
\hline $\mathbf{0 . 6 \%}$ Transaction Cost & $87.82^{* * *}$ & $56.80^{* * *}$ & $767.70^{* * *}$ \\
\hline $\mathbf{0 . 9 \%}$ Transaction Cost & $\mathrm{N} / \mathrm{A}$ & $\mathrm{N} / \mathrm{A}$ & $\mathrm{N} / \mathrm{A}$ \\
\hline
\end{tabular}

Notes: The table presents the values of the following test statistics: t-test for equality of two means, F-test for equality of two variances and a median test for equal proportion of two populations above and below median (with chi-square statistics).

*** significant at 0.01 level

$\mu_{1}, \mu_{2}$ denote mean values of $\left|M_{t}\right|$ in the first and the second sub-sample

$\sigma_{1}, \sigma_{2}$ denote variances of $\left|M_{t}\right|$ in the first and the second sub-sample

$F_{1}(x), F_{2}(x)$ denote distributions of $\left|M_{t}\right|$ in the first and the second sub-sample

N/A - not available

Source: Authors' calculations

In order to corroborate these findings, statistical tests were performed, verifying the hypotheses on the equality of means and variances, as well as a median-based distribution test (Table 3). At the transaction cost levels of $0 \%, 0.3 \%$, and $0.6 \%$, the results demonstrate that after the introduction of the new regulations on short selling on the WSE, significant changes occurred with respect to the mean level, volatility, and distribution of mispricing series. Tests were not performed for transaction costs of $0.9 \%$ due to an insufficient number of observations in the second sub-period.

In order to study how short sale restrictions on the WSE equity market affected the level of mispricing of WIG20 futures, the regression equations, described by Equation 3, were also estimated and presented in Table 4 . The parameter standing next to the dummy variable representing the influence of short sale restrictions was statistically significant and positive under all transaction cost variants except $0.9 \%$. This means that values of this variable equal to 1 correspond to higher levels of mispricing, which confirms the results of previous analyses. In the equation corresponding to transaction costs of $0.9 \%$, the $\alpha_{2}$ parameter is not statistically significant, but it should be taken into account that here the $D_{i}$ variable was 0 only in the case of a single observation, and 1 in the remaining 87 out of 88 . Time to maturity was a factor significantly affecting the absolute level of mispricing, but only in the equations estimated at cost levels of $0 \%$ and $0.3 \%$. The parameter $\alpha_{1}$ is positive in these instances, meaning that the closer the moment of contract expiration, the lower the level of mispricing. In the cases of higher transactional costs, the correlation was not statistically significant. Regression analysis did not show, however, that the level of over- and underpricing of WIG20 futures was affected by volatility. Only in one equation, estimated at the cost level of $0.9 \%$, the parameter standing next to the $\mathrm{Vol}_{i}$ variable was statistically significant. 
Table 4 | Regression Results for the Effect of Various Factors on the Absolute Mispricing

\begin{tabular}{|l|l|l|l|l|l|l|}
\hline & $\boldsymbol{a}_{\mathbf{0}}$ & $\boldsymbol{a}_{\mathbf{1}}$ & $\boldsymbol{a}_{\mathbf{2}}$ & $\boldsymbol{a}_{\mathbf{3}}$ & $\boldsymbol{R}^{\mathbf{2}}$ & $\boldsymbol{N}$ \\
\hline $\mathbf{0 . 0 \%}$ & 0.000083 & $0.000066^{* * *}$ & $0.003503^{* * *}$ & 0.138658 & 0.264 & 498 \\
\hline $\mathbf{0 . 3 \%}$ & $0.002018^{* * *}$ & $0.000053^{* * *}$ & $0.002882^{* * *}$ & 0.358041 & 0.180 & 393 \\
\hline $\mathbf{0 . 6 \%}$ & $0.004959^{* * *}$ & 0.000026 & $0.003038^{* * *}$ & 2.625238 & 0.127 & 174 \\
\hline $\mathbf{0 . 9} \%$ & $0.008386^{* *}$ & 0.000022 & 0.001950 & $4.063261^{*}$ & 0.053 & 88 \\
\hline
\end{tabular}

Notes: The table presents the estimates for the Equation 3:

$*^{*},{ }^{* * * * *}$ significant at $0.1,0.05$ and 0.05 level, respectively.

Source: Authors' calculations

\section{Conclusions}

Based on the results of the analysis carried out, it may be concluded that on the Polish stock exchange, after regulatory changes dealing with short sale constraints, the market prices of futures became more converged with the no-arbitrage pricing level. There was a decline both in the number of mispricing occurrences and in the mean level and dispersion of deviations from the fair values, especially with regard to underpriced contracts. These results can be attributed to enhanced short arbitrage between the spot and futures market. The arbitrage opportunities were virtually absent in this period for investors bearing the highest transaction costs. Nevertheless, it cannot be stated that the arbitrage mechanism regulating the mispricing of futures on the Warsaw Stock Exchange is fully effective, as arbitrage opportunities still occur for large institutional investors. However, they occur much less frequently than before July 1, 2010. It has been found that short sale restrictions on the WSE spot market were an important factor responsible for the high level of WIG20 futures mispricing, which changed after the introduction of short sale facilitations. At the same time, the study suggests that the level of mispricing may not be attributed to volatility, but rather to the time to maturity.

At an earlier stage of operation of the Polish stock exchange, it was determined that it displays the characteristics of a mature market in terms of ex post and ex ante violations for short arbitrage, but not in terms of long arbitrage (Białkowski and Jakubowski, 2008). Upon the introduction of changes allowing institutional investors to participate in the futures market, arbitrage opportunities were further reduced (Bohl et al., 2011). The present study, analysing ex post arbitrage opportunities, shows that the subsequent change introduced on the WSE - the lifting of short sale constraints - has increased the efficiency of the futures market.

\section{References}

Ackert, L. F., Athanassakos, G. (2005). The Relationship between Short Interest and Stock Returns in the Canadian Market. Journal of Banking \& Finance, 29(7), 1729-1749. DOI: 10.1016/j.jbankfin.2004.06.034.

Aitken, M. J., Frino, A., McCorry, M. S., Swan, P. L. (1998). Short Sales Are Almost Instantaneously Bad News: Evidence from the Australian Stock Exchange. Journal of Finance, 53(6), 2205-2223. DOI: 10.1111/0022-1082.00088. 
Andani, A., Lafuente, J. A., Novales, A. (2009). Liquidity and Hedging Effectiveness under Futures Mispricing: International Evidence. Journal of Futures Markets, 29(11), 1050-1066. DOI: 10.1002/fut.20395.

Asquith, P., Pathak, P., Ritter, J. R. (2004). Short Interest and Stock Returns. National Bureau of Economic Research, Inc. Working Paper Series No. 10434. DOI: 10.3386/w10434.

Białkowski, J., Jakubowski, J. (2008). Stock Index Futures Arbitrage in Emerging Markets: Polish Evidence. International Review of Financial Analysis, 17(2), 363-381.

DOI: 10.1016/j.irfa.2006.10.004.

Bohl, M. T., Goodfellow, Ch., Bialkowski, J. (2010). Individual Investors Surpass Their Reputation: Trading Behaviour on the Polish Futures Market. Economic Systems, 34(4), 480-492. DOI: 10.1016/j.ecosys.2009.12.003.

Bohl, M. T., Salm, Ch. A., Schuppli, M. (2011). Price Discovery and Investor Structure in Stock Index Futures. Journal of Futures Markets, 31(3), 282-306. DOI: 10.1002/fut.20469.

Brailsford, T. J., Cusack, A. J. (1997). A Comparison of Futures Pricing Models in a New Market: The Case of Individual Share Futures. Journal of Futures Markets, 17(5), 515-541. DOI: 10.1002/(sici)1096-9934(199708)17:5<515::aid-fut2>3.0.co;2-i.

Bris, A., Goetzmann, W. N., Zhu, N. (2007). Efficiency and the Bear: Short Sales and Markets around the World. Journal of Finance, 62(3), 1029-1079. DOI: 10.1111/j.1540-6261.2007.01230.x.

Buhler, W., Kempf, A. (1995). Dax Index Futures: Mispricing and Arbitrage in German Markets. Journal of Futures Markets, 15(7), 833-859. DOI: 10.1002/fut.3990150706.

Butterworth, D., Holmes, P. (2000). Mispricing in Stock Index Futures Contracts: Evidence for the FTSE 100 and FTSE Mid 250 Contracts. Applied Economics Letters, 7(12), 795-801. DOI: $10.1080 / 135048500444822$.

Chan, K., Kot, H. W., Yang, Z. (2010). Effects of Short-Sale Constraints on Stock Prices and Trading Activity: Evidence from Hong Kong and Mainland China. DOI: 10.2139/ssrn.1572067. [Retrieved 2014-11-30] Available at: http://ssrn.com/abstract=1572067

Charoenrook, H., Daouk, A. (2005). A Study of Market-Wide Short-Selling Restrictions. Cornell University, Department of Applied Economics and Management Working Paper No. 51180. DOI: 10.2139/ssrn.687562.

Chow, Y-F., McAleer, M., Sequeira, J. M. (2000). Pricing of Forward and Futures Contracts. Journal of Economic Surveys, 14(2), 215-253. DOI: 10.1111/1467-6419.00110.

Copeland, L., Elliott, J. T. (2013). The Effects of the 2008 Short-Sales Ban. Journal of Financial Regulation \& Compliance, 21(4), 334-352. DOI: 10.1108/jfrc-11-2012-0045.

Cornell, B., French, K. R. (1983). Taxes and the Pricing of Stock Index Futures. Journal of Finance, 38(3), 675-694. DOI: 10.2307/2328076.

Diamond, D. W., Verrecchia, R. E. (1987). Constraints on Short-Selling and Asset Price Adjustment to Private Information. Journal of Financial Economics, 18(2), 277-311. DOI: $10.1016 / 0304-405 \times(87) 90042-0$.

Figlewski, S. (1981). The Informational Effects of Restrictions on Short Sales: Some Empirical Evidence. Journal of Financial and Quantitative Analysis, 16(4), 463-476. DOI: $10.2307 / 2330366$.

Fung, J. K., Jiang, L. (1999). Restrictions on Short-Selling and Spot-Future Dynamics. Journal of Business Finance and Accounting, 26(1-2), 227-248. DOI: 10.1111/1468-5957.00254.

Graff, G., Kaczkowska, A. (2013). The Efficiency of Polish Stock Market: Ordinal Patterns Approach. Acta Physica Polonica, 123(3), 526-528. DOI: 10.12693/aphyspola.123.526. 
Hemler, M. L., Longstaff, F. A. (1991). General Equilibrium Stock Index Futures Prices: Theory and Empirical Evidence. Journal of Financial and Quantitative Analysis, 26(3), 287-308. DOI: $10.2307 / 2331208$.

Hsu, H., Wang, J. (2004). Price Expectation and the Pricing of Stock Index Futures. Review of Quantitative Finance and Accounting, 23, 167-184.

DOI: $10.1023 / \mathrm{b}$ :requ.0000039510.16484.21.

Kempf, A. (1998). Short Selling, Unwinding, and Mispricing. Journal of Futures Market, 18(8), 903-923. DOI: 10.1002/(sici)1096-9934(199812)18:8<903::aid-fut2>3.3.co;2-m.

Kern, S. (2010). Short Selling. Important Business in Need of Globally Consistent Rules. Deutsche Bank Research Research Briefing, 17 March.

MacKinlay, C. A., Ramaswamy, K. (1988). Index-Futures Arbitrage and the Behavior of Stock Index Futures Prices. The Review of Financial Studies, 1(2), 137-158.

DOI: $10.1093 / \mathrm{rfs} / 1.2 .137$.

McMillan, D. G., Ülkü, N. (2009). Persistent Mispricing in a Recently Opened Emerging Index Futures Market: Arbitrageurs Invited. Journal of Futures Markets, 29(3), 218-243. DOI: 10.1002/fut.20355.

Pope, P. F., Yadav, P. K. (1994). The Impact of Short Sales Constraints on Stock Index futures Prices. Evidence from FT-SE 100 Futures. The Journal of Derivatives, 1(4), 15-26. DOI: $10.3905 /$ jod.1994.407895.

Potocki, T., Swist, T. (2012). Empirical Test of the Strong Form Efficiency of the Warsaw Stock Exchange: The Analysis of Wig 20 Index Share. South-Eastern Europe Journal of Economics, 2, 155-172.

Ramaswamy, K., Sundaresan, S. M. (1985). The Valuation of Options on Futures Contracts. Journal of Finance, 40(5), 1319-1340. DOI: 10.2307/2328115.

Strawinski, P., Ślepaczuk, R. (2008). Analysis of High Frequency Data on the Warsaw Stock Exchange in the Context of Efficient Market Hypothesis. Journal of Applied Economic Sciences, 3(5), 306-319.

Wagener, M., Kundisch, D., Riordan, R., Rabhi, F., Herrmann, P., Weinhardt, Ch. (2010). Price Efficiency in Futures and Spot Trading: The Role of Information Technology. Electronic Commerce Research and Applications, 9(5), 400-409. DOI: 10.1016/j.elerap.2010.04.002.

Wang, J., Hsu, H. (2006). Price Expectation and the Pricing of Stock Index Futures: Evidence from Developed and Emerging Markets. Review of Pacific Basin Financial Markets and Policies, 9(4), 639-660. DOI: 10.1142/s0219091506000884.

Wang, J. (2010). Short Selling and Index Arbitrage Profitability: Evidence from the SGX MSCI and TAIFEX Taiwan Index Futures Markets. Emerging Markets Finance \& Trade, 46(5), 48-66. DOI: $10.2753 /$ ree1540-496x460504.

Woolridge, J. R., Dickinson, A. (1994). Short Selling and Common Stock Prices. Financial Analysts Journal, 50(1), 30-38. DOI: 10.2469/faj.v50.n1.20.

Yadav, P. K., Pope, P. F. (1994). Stock Index Futures Mispricing: Profit Opportunities or Risk Premia? Journal of Banking and Finance, 18(5), 921-953.

DOI: 10.1016/0378-4266(94)00026-3.

Zhang, Z., Lai, R. (2006). Pricing Efficiency and Arbitrage: Hong Kong Derivatives Markets Revisited. Applied Financial Economics, 16(16), 1185-1198.

DOI: 10.1080/09603100500447552. 